\title{
Training in online search skills at Sokoine University of Agriculture, Tanzania: the use of TEEAL and AGORA databases
}

\author{
Chilimo Wanyenda. L. \\ Sokoine University of Agriculture Library, P. O. Box 3022, Morogoro, Tanzania: \\ wchilimo@yahoo.com
}

\begin{abstract}
TEEAL and AGORA databases form an important part of the electronic resources at Sokoine National Agricultural Library in Tanzania (SNAL). This paper presents strategies that SNAL has used to ensure that students, academic staff and researchers at SNAL develop effective online search strategies that help them make effective use of various electronic resources including TEEAL, AGORA databases and other electronic resources. Major training methods are the use of formal and informal Information Literacy (IL) programmes, seminars and workshops and other innovative strategies like developing online tutorials. Some of these strategies have not only been essential in imparting online research skills to library users but also they have been important as a marketing strategy for these resources. The paper also discusses challenges and opportunities that are presented with the use of these databases, particularly in the context of university libraries in developing countries. Recommendations on how to improve the situation are made.
\end{abstract}

\section{Introduction}

The advancement in information and communication technologies (ICTs) and the increasing provision of electronic journal collections has forced libraries and librarians to develop new services and adapt working practices, which provides a number of challenges to librarians in terms of the new skills that they are required to possess, and the appropriate cultural changes which need to be assimilated. The new digital environment in which many libraries are now operating also require library users to develop information-searching skills and effective online search competences. These skills are critical for effective and efficient retrieval of information from the available databases and are especially important because information is becoming more voluminous, fragmented into different formats and media, and duplicated in multiple physical locations. Thus, in order to effectively access and use these myriad information sources, people must be information literate (Ercegovac and Yamasaki, 2004).

A number of authors including Neely (2002); Eisenberg, Lowe and Spitzer (2004) 
attributed the term information literacy to Zurkowski, President of the Information Industry Association, who used the term information literates in 1974 to identify people "trained in the application of information resources of their work". According to ALA (1998), to be information literate a person must be able to recognise when information is needed and have the ability to locate, evaluate and use effectively the needed information. Therefore IL is a service programme that has mainly been brought about by the advancements in ICTs. The more electronic resources libraries acquire and make available to users, the greater the demand for instruction on how to access and use those resources effectively and efficiently.

This paper discusses the role that IL programmes can play in developing the online search competence of the library users. The discussion will be based on SNAL's experience with the use of TEEAL and AGORA and other electronic resources.

SUA is a reputed university in Africa dealing with the disciplines of agriculture and related fields. It became a fully-fledged university in July 1984, having been the Faculty of Agriculture, Forestry, and Veterinary Science of the University of Dar es Salaam. The University has four faculties and one constituent college. It has more than 2,000 students and about 240 academic staff. As a matter of fact, the university also has a computer centre which was established in 1993.

\section{Literature Review}

Online search strategy represents skills and competencies required in order to effectively learn and conduct search activities using the information available in electronic format. They involve skills which can help academicians stay up to date in their field and successful in their applied research (Wright and Howell, 2004). The starting point for the development of such competence is for a person to be information literate. According to Engeldinger (1998), an information-literate person has a number of qualities and skills. An information-literate person recognizes when he/she has an information needs, knows the appropriate places to look for information, and knows the appropriate strategies to use 
for each of them. The information-literate person has the ability to recognize the information when it is found, and then to determine if it is the best, most accurate or most current information available. An information-literate person knows how to communicate information, share it collaboratively and use it ethically.

Institutions of higher learning follow a variety of approaches in teaching IL. Some of these approaches include IL courses which range from credit to non-credit and from compulsory to elective (Ashoor, 2005). Other approaches include the integration of IL in the various course curricula. IL can also be taught informally meaning that it could be completely out side the curriculum (Donnelly, 1998). The methods of conducting / teaching IL can also take a variety of forms, e.g. advice to individuals during the reference interview process, individualized instruction, in-depth research consultations and appointments, group instruction in traditional or electronic classrooms, course management software, Web tutorials and Web-based instruction (ACRL, 2003).

Web-based programs designed to introduce students to general information literacy concept and resources have gained popularity in recent years (Sheer and Pasqualoni, 2002; Vander, 2002). Various institutions have also developed such tutorials, examples of which can be found in the following institutions: University of Texas, Queensland University of Technology in Australia and Rutgers University. (University of Texas, 2004; Queensland University of Technology, 2005; Rutgers University Library, 2005). Examples in Africa include INFOLIT (Cape Technicon Library Services, South Africa)

\section{Experiences from the Sokoine University of Agriculture}

The Sokoine University of Agriculture has a Local Area Network (LAN) based on fibre optic backbone running at 100mbps and an Internet connection through a lease line. The university has a library which also serves as a national agricultural library known as the Sokoine National Agricultural Library (SNAL). As a university library and a national agricultural library, SNAL, serves various categories of users including university staff, students, researchers, extension workers, farmers and the community at large. SNAL started to automate its services in 1998, and the catalogue and the circulation system have 
now been automated. The automation was initially done using CDS /ISIS software. However, the library has now migrated to an integrated web-based library automation system called WEBLIS.

SNAL offers a number of electronic information services to its users which include: Online Public Access Catalogue (OPAC); over 180 CD-ROM databases with either abstract or full-text information for agriculture and allied subjects; the Essential Electronic Agricultural Library (TEEAL); Electronic Journal resources through International Availability of Scientific Publications (INASP), AGORA and HINARI; Question and Answer services (Q\&A) sponsored by CTA; and the E-granary database which is a digital library that was designed to assist libraries and institutions lacking adequate Internet access. E-granary is a full-text database of about 120 Gigabytes.

\section{The Essential Electronic Agricultural Library (TEEAL) Database at SNAL}

SNAL acquired its first set of TEEAL CD-ROMs in April 2000 through government funding. This first version of TEEAL had journals covering the years 1993 to 1997. The whole set of TEEAL CDs were kept in the library under the supervision of the periodical section.

The TEEAL index was installed in all the computers in the Library computer room. TEEAL index was also installed in other places within the university including all common computer rooms/labs in the faculties. TEEAL index was also installed in individual lecturers' offices who requested it, as well as in the offices of the Vice Chancellor and Deputy Vice Chancellor. The aim of this exercise was to enable users to search the TEEAL bibliographic information from their offices and only come to the library to print full-text articles. During this time, the library publicized TEEAL using its Current Awareness Services (CAS) such as the library noticeboards, the university mailing list, etc. 
In 2003 the library was able to purchase the updated version of TEEAL (i.e. up to 2001) through NORAD ${ }^{1}$ support. In January 2006, through government funding SNAL acquired an updated version of TEEAL (LanTEEAL) with journals published up to 2004. Two units of LanTEEAL have been purchased for installation at the main library and branch Library at Solomon Mahlangu Campus. Currently the library, in collaboration with the university computer centre is working on the mechanisms and technical aspects required to put the LanTEEAL into operation. The library is also in the process of purchasing the relevant hardware which is required for the smooth running of the LanTEEAL. The LanTEEAL that SNAL purchased permits up to ten users at a time.

Feedback from TEEAL users has on the whole been positive. Students, lecturers and researchers in various agricultural-related specializations find the database useful and relevant. The off-line attribute of TEEAL has also been very useful because of the low bandwidth that the university has (i.e. 128 kbps uploading and 256 kbps downloading). Furthermore, internet connectivity and power supply at SUA are not reliable. All these factors affect the usage of the electronic resources in the library. Further, the major problem which the library faces in using TEEAL is that of inadequate funds which makes the library unable to acquire updates whenever they are available.

\section{Access to Global Online Resource in Agriculture (AGORA) database at SNAL}

SNAL began to access the AGORA database in October, 2003. Journals available in the AGORA database are very relevant to agricultural institutions like SUA. The use of AGORA and TEEAL databases at SNAL complement each other very well. On the one hand, while it is possible to get current articles from AGORA database, slow internet connectivity limits its efficient use. On the other hand, articles from TEEAL can be efficiently downloaded but getting current issues on time is problematic. In addition, the TEEAL database is normally updated annually, and so it may not be possible to obtain current updates of the same.

\footnotetext{
${ }^{1}$ NORAD is supporting various activities throughout the university. The Library is one component of NORAD support at Sokoine University of Agriculture. Through NORAD support SNAL has also been able to acquire various ICT facilities.
} 


\section{Information Literacy at SNAL: a historical perspective}

Up to around 1999, SNAL was only providing library orientation programmes to first year undergraduate students at the beginning of each semester. However, with automation of the library and the availability of various electronic information sources, it was important to start information literacy (IL) programmes. The aim is to equip users with skills on how to access and use information from various electronic resources in the library. Efforts to introduce an IL programme at SUA started in 1999 and it was taught as a topic in the communication skills course. This is a compulsory and examinable course for all undergraduates during their first year. This arrangement went smoothly for only two years before it was stopped unofficially in 2002. According to Dulle and Lwehabula (2004), the IL programme was discontinued for the following reasons: (1) Lack of understanding among stakeholders of what information literacy is; (2) Little involvement of stakeholders in introducing the programme; (3) Change in leadership of the head of department hosting the communication skills course; (4) Librarians were not aggressive enough to continue the efforts that were initiated; (5) It was not officially recognized within the academic framework of the university. During the same period the library was increasingly acquiring electronic resources and it was found out that the utilization of these e-resources was minimal, mainly due to lack of IL skills among the users. Adam and Wood (1999); Dulle and Lwehabula (2004) pointed out that lack of IL skills in many African countries is one of the major causes of underutilization of the existing ICTs in many libraries. Thus the libraries are forced to adopt multi-approaches in order to deliver IL.

\section{Information Literacy at SNAL: the current situation}

To facilitate the delivery of IL programes, SNAL currently acquired an LCD projector. The training is conducted in the library computer room with 22 computers, providing an opportunity for hands-on practice. SNAL uses various IL programmes to ensure that students, academic staff as well as researchers at SUA develop effective online search skills. Such skills help them make effective use of the TEEAL, AGORA databases and other electronic resources. IL programmes include: informal IL programmes for postgraduate students, informal IL programmes for undergraduates, IL programmes for junior 
academic staff, IL programmes for other agricultural researchers and online tutorials. Below is a detailed description of these IL methods.

First, SNAL conducts informal information literacy programmes / seminars for postgraduate students at the beginning of every academic year. These programmes are always promoted through announcements on notice boards to invite Postgraduate (Masters and $\mathrm{PhD}$ ) students to register for the IL programs in the library. This programme was well received by students to the extent that, other students who did not attend came to the library to request IL training. Between October and December 2005, the library trained 60 postgraduate students. TEEAL and AROGA databases are always an important part of these programmes.

Second, following the observation that the orientation programme provided to the undergraduate students is not adequate to impart the necessary IL skills, SNAL introduced informal IL programme for undergraduate students starting from the 2005/2006 academic year. Training is conducted during the first semester. Participation of students is coordinated by class representatives. Two hundred and sixty two first-year undergraduate students were trained in the academic year 2005/2006 through this programme. Being an off-line system, TEEAL database was a very important component of the training that was provided to undergraduate students. This is because when the library was conducting this training for undergraduate students the Solomon Mahlangu Campus, where all the first-year students reside, was going through a long period of Internet problems which left the campus without Internet connectivity for over a year. Thus, one of the objectives of the training was to promote usage of the off-line electronic resources which were available in the library, including TEEAL.

Based on the feedback that the library has been receiving from the students about this particular IL programme for undergraduate students, it was found that the training was useful to students and the number of students who come to the library to request information from either TEEAL, CD-ROMS or E-granary has dramatically increased. The observation of students' activities in the library also revealed that first year students 
were able to use various resources like OPAC more easily than to before the training.

Third, the University management at SUA, in collaboration with the Bureau for Agricultural Consultancy and Advisory Services (BACAS), has been organizing IL workshops for newly employed academic staff at SUA. BACAS is a consultancy arm of the Faculty of Agriculture at SUA. Library staff participates in facilitating such workshops by training these newly employed academic staff on how to use various electronic sources of information available in the library including TEEAL and Agora databases. They are also taught how to evaluate the information obtained from such sources. Three workshops were conducted between November 2005 and March 2006.

With the support of INASP, SNAL conducted more workshops for academic staff, researchers and postgraduate students at SUA. In July 2007 a workshop was conducted on how to use various electronic resources available at SNAL that involved 42 SUA staff and 40 Postgraduate students.

Fourth, the Ministry of Agriculture also periodically organises workshops for its researchers from various agricultural research institutions all over the country. SNAL staff, in collaboration with the BACAS, organized a workshop in May 2005 for these researchers. IL was one of the main topics in that workshop.

Fifth, SNAL's online IL tutorials constitute a web-based IL program designed to introduce library users to the general information literacy concept. These tutorials are accessible from the library website ${ }^{2}$. The notes for online IL training were locally developed by the library staff. However, the library is looking for means to make them interactive so that the library users can be motivated to use these tutorials. Currently, these tutorials are not interactive, and so their impact on improving the scientists' IL skills is still insignificant and also their use cannot be monitored.

\footnotetext{
2 Sokoine National Agricultural Library online tutorials can be accessed from: http://snalwww.suanet.ac.tz
} 


\section{Content of IL Programmes}

The content of IL programmes at SUA normally varies depending on the audience and their computer literacy levels. On the one hand, the majority of undergraduate students have little computer skills and some of them are completely ignorant regarding computer use. Therefore the programme content for the first sessions is normally at an elementary level, which includes creating awareness of what sources are available, constructing simple search queries, etc. On the other hand, postgraduate students, academic staff and researchers are provided with in-depth training in IL. Generally IL programmes at SUA cover topics such as general search strategies, how to find information from various sources, how to evaluate the information found, how to locate materials in the library, how databases are structured, effective internet searching, citing electronic information resources, effective use of Boolean operators and much more.

\section{IL as a marketing strategy}

The IL programmes provided to various user categories at SNAL are a good opportunity for the library to market and publicise its services, including TEEAL and AGORA databases. The IL programmes at SNAL succeeded in creating demand for the existing services, so that many users are now coming to the library to request for the electronic information resources. In many higher learning institutions, the potential library users are unaware of the services available in the library. A challenge for any library is to keep its customers aware of the range of services that the library offers. Hence, a successful library needs to continuously market its services and competencies. Donald (2006) emphasizes that if librarians do not "blow their own trumpets"; library services may only be appreciated by a few. A successful marketing programme of the library can create awareness of and desire for its services, build an understanding of the value of the services, increase the level of usage, and expand the client base (Quantum, 2006).

Therefore, together with other strategies which are currently used to promote and market library services, SNAL has also made great use of the opportunity provided by the IL programmes as deliberate efforts to 'market' its e-resources. As a matter of fact, there have been improvements in the general image of library services as well as the usage of 
the various e-resources.

\section{Challenges experienced}

Despite numerous efforts made by librarians, SNAL still face a number of challenges in delivering IL programmes and in developing online search competencies of their users.

First, most of the undergraduate students do not have the basic knowledge of how to use computers; hence training these students in IL is a challenge. However, through the IL training most of them are being motivated to go and acquire the basic knowledge of how to use computers.

Second, since IL programmes for students are organized informally it is only possible to conduct them at the beginning of the semester when students are not very busy. It is difficult to conduct the IL training in the middle of the semester because of the increased workload. Hence, the time available for students to attend IL sessions is very limited, whereas there is a lot to be covered as far as IL training is concerned.

Third, there are inadequate staffing levels at SNAL because a large proportion of staff is on study leave and there is high labour turnover. For example, currently SNAL has only four academic staff that is supposed to administer the library as well as to conduct all these types of IL training.

Fourth, SNAL faces challenges in conducting IL training due to lack of space in the library. At the moment the library has only one computer room that is used for both training and internet and CD-ROM searches by users. Therefore, when the IL sessions are taking place, students are not able to use the computer room for internet and CDROM searches.

Fifth, currently the whole university has about 320 computers in total with significant improvements for the academic staff. Currently, the ratio of computers to academic staff at SUA stands at 1:1. However, a lot needs to be done to improve access to computers 
for students. For instance, at the moment there are only two computer training laboratories with about 60 computers each for the entire student population, which is around 2,500. The current computer-student-ratio at SUA stands at 1: 40. Furthermore, the number of students is increasing very fast, implying that the computer laboratory for students needs to be equipped with more computers and more LAN points and hubs.

Sixth, low bandwidth discourages most of the library users in the universities from attending the IL training. The meeting between SUA and ASARECA staff, which was held in 2004, revealed that most users at SUA complain about spending a lot of time downloading only one document from the internet.

Seventh, university administration is not committed to IL programmes. For example, the integration of IL into the various course curricula is an initiative that has not been supported by the administration.

Finally, staff attitudes and technophobia is another challenge that is making it difficult for IL to be on a firm footing at the university. Most academicians are satisfied with traditional methods of accessing information, for which most of the time they ask the libraries to conduct an information search for them and would even demand payment to attend IL training workshops.

\section{Conclusion}

The role of IL programmes in developing online search strategies and skills for library users cannot be over emphasised. SNAL is using a number of IL approaches to ensure that users not only develop online search skills but also become information literate. However, to achieve this goal there are still a lot of challenges that need to be addressed as discussed above. Librarians should take a leading role to ensure that IL programmes are effectively implemented and sustained.

\section{Recommendations}

This paper makes the following recommendations: 
- There is a need to develop a policy and implementation plan on integration of IL training in the course curriculum which will make IL training mandatory.

- More awareness programmes are needed to educate the university community about the importance of the IL training such as through posters, stickers, newsletters etc.

- Both short-term and long-term training approaches should be used

- IL should be a continuous training and retraining programme

- Librarians should ensure follow up activities and evaluation after the training

- Libraries should introduce a virtual or physical enquiry service for IL-related queries.

- Librarians should define strategies that ensure that there is a backup for the library staff in order to ensure continuous IL training.

- Librarians should also target Deans/Directors of departments to be champions of IL integration into the curriculum

- Efforts should be made to prepare librarians to become effective teachers of IL programmes through in-house training, seminars/workshops and long-term training courses

- Librarians, educators and administrators should play a leadership role in the development and implementation of IL programmes; new relationships should also be developed throughout the educational community to work towards IL curriculum development (ACRL 2004).

- Development of local content is also important as it will encourage both students and the academicians to access information on the internet, since they will also be accessing their own information. Thus, digital institutional repositories, which include both published and unpublished publications of the university staff, should be put in place.

\section{References}

Adam, L. and Wood, F. (1999). "An investigation of the impact of information and communications technologies in Sub-Saharan Africa," Journal of Information Science, 25 (4), 307-18.

American Library Association (ALA). (1998). Presidential committee on information literacy: Final report. Chicago: American Library Association. 
Ashoor. M. (2005). "Information literacy: a case study of KFUPM library.” The Electronic Library, 23 (4), 398-409.

Association of College and Research Libraries (ACRL). (2004). Best practices and assessment of information literacy programs. Institute for information literacy. <http://www.earlham.edu/ libr/Plan.htm> (Accessed 20 March 2006).

Association of Research and Academic Libraries (ACRL). (2003). Guidelines for instruction programs in academic libraries.

$<$ http://www.ala.org/ala/acrl/acrlstandards/guidelinesinstruction.htm>

(Accessed 20 March 2006).

Donald, R. (2006). Marketing: A challenge for corporate librarians.

$<$ http://www.insitepro.com/donald3.htm> (Accessed 20 ${ }^{\text {th }}$ March 2006).

Donnelly, K.M. (1998). Learning from the teaching libraries. American Libraries, 29(11) pp.47.

Dulle F.W. and Lwehabura, M.J.F. (2004). User information literacy: Challenges facing university libraries towards effective implementation. Paper presented at the $6^{\text {th }}$ standing conference of African national and university libraries. $30^{\text {th }}$ June $2004-3^{\text {rd }}$ July 2004 , Kampala, Uganda.

Eisenberg, M.B., Lowe, C.A. and Splitzer, K.L. (2004). Information literacy essential skills for information age (2nd ed.). Westport: Library Unlimited.

Ercegovac, Z. and Yamasaki, E. (2004). Information literacy: Search strategies, tools \& Resources. <http://www.libraryinstruction.com/infosearch.html> (Accessed $20^{\text {th }}$ March 2006).

Engeldinger, E.A. (1998). "Bibliographic instruction and critical thinking: The contribution of the annotated bibliography,”RQ Winter, 28 (2), 195-202.

Neely, T. Y. (2002). Sociological and psychological aspects of information literacy in higher education. London, Maryland: Scarecrows Press.

Rutgers University library. (2005). Online tutorials.

$<$ http://www.libraries.rutgers.edu/rul/lib_instruct/instruct_tutorials.shtml $>$ (Accessed $25^{\text {th }}$ March 2006). 
Queensland University of Technology. (2005). Information literacy | Online tutorials. $<$ http://www.library.qut.edu.au/infolit/tutorials/> (Accessed $25^{\text {th }}$ March 2006).

Quantum, (2006). Marketing library services: Packaging, promoting and persuading. $<$ http://quantum.dialog.com/q2_resources/whitepapers/marketing_library_svc.pdf $>$ (Accessed 20 $0^{\text {th }}$ March 2006).

Sheer, A.K. and Pasqualoni, M. (2002). "Information literacy instruction in higher education, trends and issues", ERIC Digest, June.

University of Texas. (2004). Texas Information Literacy tutorials. $<$ http://tilt.lib.utsystem.edu/ $\geq$ (Accessed $25^{\text {th }}$ March 2006).

Vander Meer, P.F. (2000). "Pushing the limits: creative web use in libraries related to instruction, research strategies," Research Strategies, 17 (4), 237-56.

Wright, T.C. and Howell, S. L. (2004). Ten Efficient Research Strategies for Distance Learning, Online Journal of Distance Learning Administration. 7(1)http://www.westga.edu/distance/ojdla/spring71/wright71.html (Accessed 20 ${ }^{\text {th }}$ March 2006). 